\title{
Schedule induction and the temporal distributions of adjunctive behavior on periodic water schedules
}

\author{
ALLISTON K. REID \\ Duke University, Durham, North Carolina \\ and \\ PATRICIA PIÑONES VAZQUEZ and JAVIER ALATORRE RICO \\ Universidad Nacional Autónoma de México, México, D.F., Mexico
}

\begin{abstract}
The ability of periodic water reinforcement schedules to induce or entrain activities was investigated by having observers classify mutually exclusive and exhaustive activities of 10 rats placed in a rich environment with various fixed-time schedules of water delivery. For each activity measured, three characteristics of induced behavior were examined: (1) its excessiveness; (2) the commonly observed inverted-U relation between rate of induced behavior and rate of reinforcement; and (3) the observation that induced activities occur earlier in interreinforcement intervals than do facultative activities, producing multimodal activity distributions. All activities were demonstrated to be noninduced, facultative activities, and none could be classified as schedule-induced behavior by any of the three criteria. The factors that determine the temporal distributions of all activities appeared to be equivalent to the factors that determine the distributions of scheduleinduced activities in situations in which only the induced activities are available.
\end{abstract}

Staddon's (1977b) model of schedule-induced behavior identifies three categories of behavior that occur on periodic reward schedules: terminal activities, which occur in the presence of stimuli correlated with reward delivery and are directed toward the acquisition of the reward; interim activities, which occur at elevated levels in the presence of stimuli correlated with low probability of reward delivery; and facultative activities, which are not induced, show an inverse relation with reward frequency (Riley, Wetherington, Delamater, Peele, \& Dacanay, 1985), and usually occur near the middle of interreinforcement intervals and always after interim activities (when interim activities are also observed in the interval).

Staddon's distinction between interim behavior and facultative behavior was made to emphasize that although both activity classes might occur within the same interreinforcement interval, only the interim activities are schedule induced, that is, excessive relative to massedreward baseline sessions due to some, as yet undetermined, property of the schedule itself (Staddon, personal communication, 1985). Although facultative activities are not excessive (by definition), their temporal distributions within the interreward intervals are important indicators

This report was supported by grants from the Universidad Nacional Autónoma de México and the Consejo Nacional de Ciencia y Tecnología in Mexico (Alliston K. Reid, principal investigator) and by grants from the National Science Foundation to Duke University (John E. R. Staddon, principal investigator). We thank John Staddon for his support while writing this report and Ken Steele for his useful discussions. Reprints may be obtained from Alliston K. Reid, Department of Computer Science, Eastern Oregon State College, La Grande, OR 97850. of how periodic reward schedules entrain, or modulate, the amounts of all activities available in the apparatus. One purpose of the present research was to provide further evidence of schedule entrainment to better understand the motivational properties of periodic schedules.

Currently, there is much debate concerning the properties of the periodic reward that are necessary for schedule induction to occur. For example, although there is agreement that schedule-induced polydipsia often occurs in rats on periodic food schedules, to what extent is schedule induction limited to food schedules? Does schedule induction occur on periodic schedules of water presentation? Several studies have addressed this question. For example, Wetherington and Brownstein (1979) placed rats on several fixed-time (FT) schedules of water delivery (see also King, 1974) and observed that although eating never occurred at levels above the massed-reinforcer baseline levels, it was influenced by the water schedule in ways similar to those of induced behavior. In particular, they argued that the similarity between the observed eating interreinforcement distributions and the distributions of schedule-induced behavior should be considered sufficient grounds for reconsidering the excessiveness criterion for the classification of schedule-induced behavior.

In Staddon's (1977b) model, interim behavior is schedule induced and facultative behavior is not. When both interim and facultative behavior are observed in an interreinforcement interval, the interim behavior occurs earlier and the overall activity distribution is multimodal (Roper, 1978; Staddon \& Ayres, 1975), the first peak representing the interim activity and at least one later peak representing the facultative activity. However, when only 
interim activities occur in the interval (for whatever reason), the resulting distribution is unimodal and the interim activity peaks near or slightly before the middle of the interval (Reid \& Dale, 1983; Staddon \& Ayres, 1975). Seemingly identical temporal distributions are observed with facultative behavior when interim activities are not present (Riley et al., 1985; Roper, 1978; Staddon \& Ayres, 1975). Running is a good example: when rats are allowed access only to the feeder area and a running wheel on periodic food schedules, the running distributions are unimodal and peak near the middle of the interval, although the amount of running on the periodic schedule is usually well below the level observed in massed-food sessions.

Second only to the excessiveness criterion, the dominant justification for the classification as induced behavior is the demonstration of an inverted-U relation between the amount or rate of the induced behavior and the rate of reinforcement (Cohen, 1975; Falk, 1971; Heyman \& Bouzas, 1980; Roper, 1980; Wetherington, 1979).

As Wetherington and Brownstein (1979) and Roper (1981) correctly point out, the issue of schedule induction becomes more complicated when an observed behavior appears to show some, but not all, of the characteristics of induced behavior. Most of the criteria for the classification as schedule-induced behavior originated when Falk (1971) noted that induced behaviors have common characteristics, an argument put forth when he outlined his reasons for considering them as making up a class of behavior (adjunctive behavior) that was different from that of operant behavior. Since there are multiple criteria for the classification of a separate class of behavior, it is probably inevitable that some activities will show only some of these properties.

In the present study, rats were placed on several periodic water schedules in a rich environment and all their behavior was recorded to make it more likely that any behavior that might be induced would be available for measurement. The purpose was to describe how periodic water schedules entrain the temporal distributions of each activity and to determine if these water schedules induced behavior. Since multiple criteria are used for the classification of schedule induction, three characteristics of schedule-induced behavior were examined for each of the nine activities recorded: (1) its excessiveness; (2) the commonly observed inverted-U relation between amount (or rate) of induced behavior and rate of reinforcement; and (3) the observation that multimodal activity distributions occur within interreinforcement intervals when rats engage in both schedule-induced (interim) and noninduced (facultative) behavior. Finally, we will describe the factors that are responsible for the observed temporal distributions of these facultative activities and compare them with those that entrain schedule-induced behavior.

\section{METHOD}

\section{Subjects}

Ten naive male Wistar rats, about 4 months old at the beginning of the experiment, were used in all phases and were maintained individually in home cages with wood chips used as bedding material. The animal room was temperature-controlled with the naturally occurring light/dark cycle. All subjects were adapted to a 23-h daily water deprivation schedule for 20 days before the beginning of the experiment.

\section{Apparatus}

Two identical Plexiglas experimental boxes $(57 \times 57 \mathrm{~cm}$ and $32 \mathrm{~cm}$ high) were used. On one wall of each box was a pine block measuring $19 \times 4 \times 1.5 \mathrm{~cm}$; on the opposite wall was a hardwarecloth receptacle containing about $100 \mathrm{~g}$ of Purina Rat Chow. A running wheel with a diameter of $32 \mathrm{~cm}$ was attached to a side wall, and a water pump that dispensed $0.16 \mathrm{ml}$ of water into a $1 \times 2 \mathrm{~cm}$ metal cup was attached to the outside of the remaining wall. A microcomputer controlled all experimental manipulations and recorded all events. Events were defined as 1-sec units signaled by two well-trained human observers, each of whom had a 10-key response pad for continuous visual observation of a single subject. A 7.5-W houselight located on the lid of each apparatus provided general illumination. The two observers sat in the darkened soundproof room with white noise on continually to mask extraneous sounds.

\section{Procedure}

Session duration was a function of the schedule of water presentation in effect; each session began with a water presentation and lasted until the 31 st presentation. Water was freely available for 25 min immediately after each experimental session. Purina Rat Chow was always freely available. The sessions were run 7 days a week.

Baseline. For eight sessions, 31 water presentations were available at the beginning of each session, each 0.16 -ml delivery contingent only upon licking of the water cup. All activities were recorded continually for the last five 30 -min sessions.

Phase 1. The 10 subjects were divided randomly into five groups of two rats each. For 34 sessions, each group was exposed to one of five fixed-time (FT) schedules of water delivery $(0.16 \mathrm{ml})$, ranging from FT $15 \mathrm{sec}$ to FT $180 \mathrm{sec}$. Table 1 depicts the order of schedule presentation. The observers recorded all activities during the last five sessions.

Phase 2. All subjects were shifted to a different FT schedule for 34 sessions. Of the five groups, three were shifted to longer FT values and two were shifted to shorter values. Otherwise, Phase 2 was identical to Phase 1.

Thus, data were collected from four subjects on each of the five FT values in the two phases.

Activity definition. Since two human observers were used to monitor all activity, extensive training was given before the experiment began. The behavioral categories, which were mutually exclusive and exhaustive, were: (1) Sniffing-Olfaction directed to a specific place in the apparatus, possibly accompanied by head movements, with at least three feet remaining on the floor. (2) WalkingMovement from one place to another in the apparatus, with or without sniffing or exploratory movements. (3) Rearing-Lifting of the body onto the hind legs, with or without contact with the walls of the apparatus but without grooming movements or contact with the water cup area. (4) Calm-Remaining in one place with little or no movement, but without "nosing"' the water cup area. (5) Grooming-Discrete contact with the paws on the facial or ab-

Table 1

Order of Schedule Presentation

\begin{tabular}{cll}
\hline Group & Phase 1 & Phase 2 \\
\hline 1 & FT 15 & FT 60 \\
2 & FT 30 & FT 90 \\
3 & FT 60 & FT 180 \\
4 & FT 90 & FT 15 \\
5 & FT 180 & FT 30 \\
\hline
\end{tabular}


dominal region or licking of the fur or tail. (6) Wheel runningAny contact with the running wheel that caused the wheel to turn. (7) Wood chewing - Any contact between the mouth and the wooden block. (8) Eating-Any contact between the mouth and the Purina Rat Chow in the food receptacle or any other place in the apparatus in which food was held in the paws or mouth and chewing movements occurred. (9) Water area-Any contact, with the front feet or face, with the water cup.

\section{RESULTS}

Figure 1 shows the average level of each activity as a function of the interreinforcement interval, that is, the number of 1-sec observations of each behavior per minute averaged across the four subjects in each interval value for the last five sessions in each condition.

The only activity that exceeded its baseline levels (at the left of the figure) was contact with the water cup. No other activity could be considered excessive, since, in most cases, the baseline levels were not reached on most of the FT schedules. On FT 90 and 180, grooming and eating slightly exceeded baseline levels, but it is doubtful if the increase represents anything more than a "floor effect" in which the baseline levels are so low that a variation of only a few seconds per session would appear as a substantial change. The reason the activities plotted as baseline rates do not sum to $60 \mathrm{sec}$, as do the rates for each of the FT values, is that the subjects often slept toward the end of the baseline sessions but never slept during any FT schedule, so sleeping is not plotted.

The commonly observed inverted-U function between the rate of schedule-induced behavior and the frequency of reinforcement is not shown by any of the recorded activities. Except for grooming, all activities maintained a constant rate of occurrence throughout all schedule values, demonstrating that the occurrence of each activity was a simple function of the available time. The rate of grooming gradually increased as the interreinforcement interval increased; but, again, it is doubtful that the increase represents anything more than a floor effect.

Figure 2 shows the observed activity interreinforcement distributions averaged across the four subjects for each schedule value. For easier comparison, the time scale for each distribution is normalized to 15 temporal bins.

In general, the distributions of all activities other than contact with the water cup formed an inverted U, beginning at their lowest level early in the interval, increasing to their maximum level near the middle of the interval, and decreasing to the end of the interval. This temporal distribution was most prominent with longer FT values, and least with FT $15 \mathrm{sec}$, the shortest value. Only four activities reached prominent levels on any of the FT schedules: eating, grooming, running, and sniffing. The levels of all other activities were so low that they will not be considered further.

The individual subject distributions are very accurately represented by these averaged distributions, since no activity was excessive or especially prominent within any part of the interval, and no activity was reliably prominent across FT interval values for any subject.

The temporal distributions of contact with the water cup were inversely related to the distributions of all the other activities: they were at their highest level soon after water

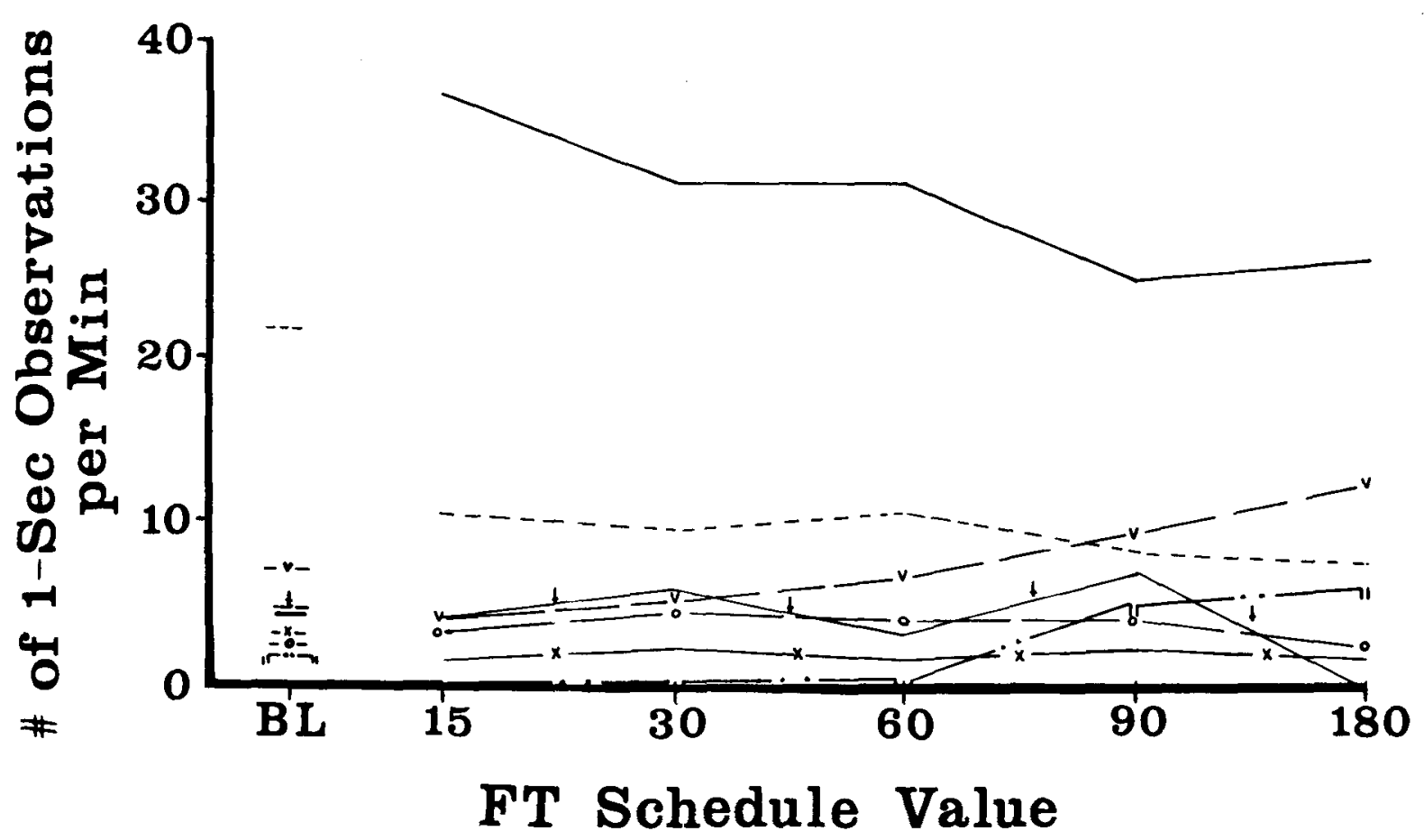

Figure 1. Average rate of each activity in terms of the number of 1-sec observations per minute as a function of the duration of the fixed-time schedule. Isolated points on the left represent average rates of each activity during the massed-reward baseline sessions. 


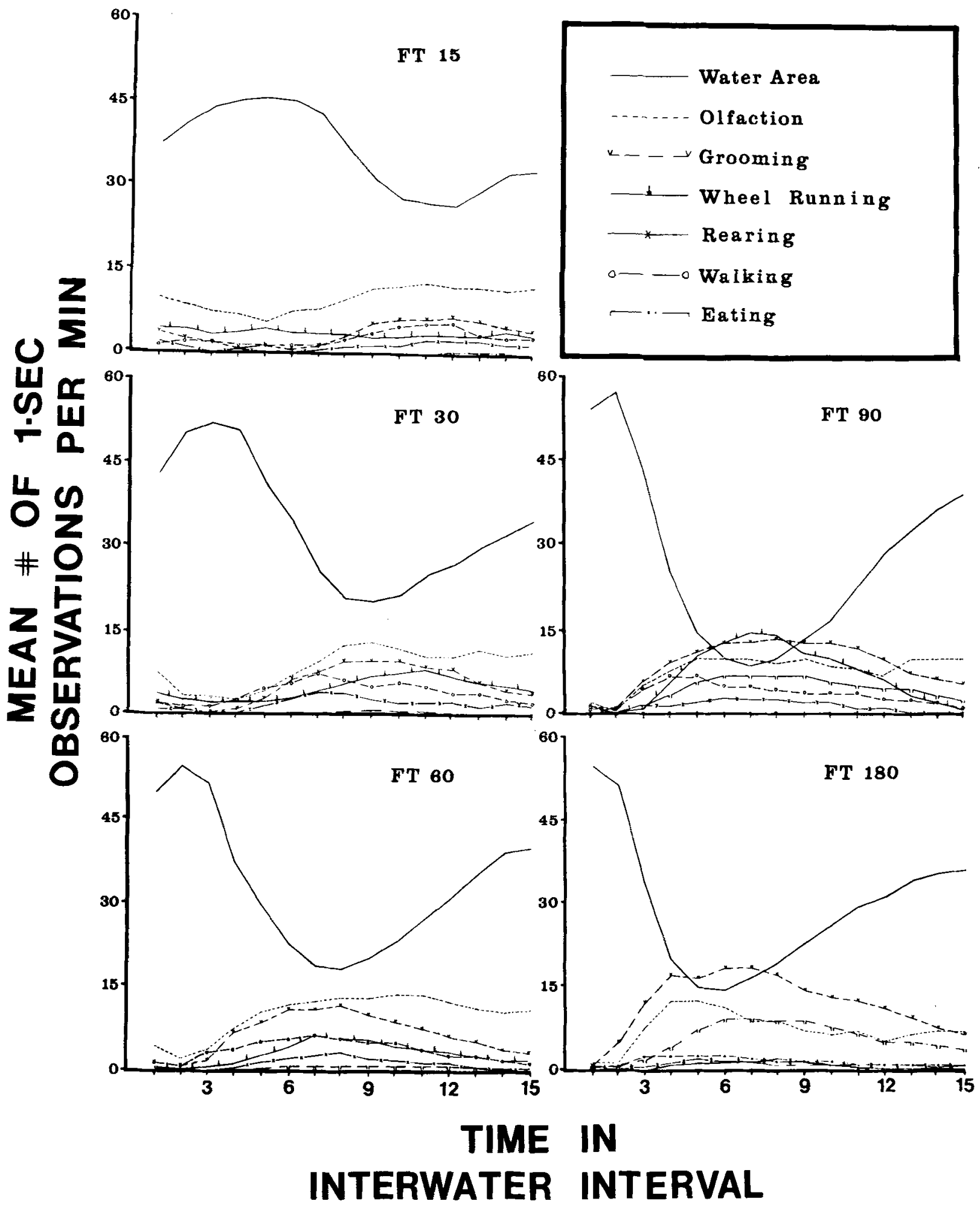

Figure 2. Average rate of each activity in terms of the number of 1 -sec observations per minute across the interreinforcement interval on various fixed-time schedules. Each curve represents the average of four rats over five sessions. Interval duration on the abscissa is divided into 15 bins for easier comparison. 
delivery, decreased to their lowest level near the middle of the interval, and increased to the end of the interval. As the duration of the interval increased, the minimum level of water cup area decreased (FT 180 was the only exception), and the maximum levels of the other activities increased proportionately (see, also, Staddon, 1977b).

The time in the interwater interval of the minimum rate of contact with the water cup was directly related to the duration of the interval (the minima shifted from 12 to $72 \mathrm{sec}$ into the interval), as was the displacement of each of the other distributions. However, the temporal displacement was not proportional to the increase in time available in each interval, resulting in a leftward shift in the maxima and minima of all distributions in Figure 2, since interval duration is normalized into 15 bins (see, also, Riley et al., 1985).

\section{DISCUSSION}

One of our major questions was whether scheduleinduced behavior occurs in rats on schedules of water presentation. We therefore placed rats in a rich environment and recorded all their behavior to make it more likely that any behavior that might be induced would be available and would be measured. There are three generally accepted characteristics of induced behavior that can be examined in the present paradigm: (1) that induced behavior is excessive relative to baseline (massed reinforcer) levels; (2) that the rate of schedule-induced behavior is an inverted-U function of the frequency of reinforcement; and (3) that if schedule-induced (interim) behavior occurs within the interreinforcement interval along with other noninduced (facultative) behaviors, the induced behavior occurs first in the interval and the facultative behavior occurs later, forming two distinct behavioral periods perhaps related to different motivational states (Staddon, 1977a, 1977b). There are other characteristics that might be considered important for proper classification, such as the ability to sustain operant responding, but such a demonstration must necessarily decrease the amount of induced behavior observed (Allison, Miller, \& Wozny, 1979; Rachlin \& Burkhard, 1978; Staddon, 1979, 1983). It is first necessary to demonstrate that the behavior does occur at excessive levels.

Figure 1 demonstrates that no activity other than contact with the water cup increased above massed-reinforcer baseline levels. Thus, by this first criterion of schedule induction, no activity appears to be schedule-induced. Contact with the water cup did, however, increase substantially above its baseline levels on all FT values, but it can be considered the terminal activity in Staddon's (1977a, 1977b) model, since it was related to obtainment of the reward.

The rates of all activities other than grooming were quite constant as FT value was varied, with grooming increasing slightly with interval duration. This independence of the rate of each activity and interreinforcement interval requires that each activity be classified as noninduced, facultative behavior. Riley et al. (1985) have demonstrated that running, another facultative activity, also increased with available time on food schedules, and running rate was an approximately constant function of the FT value.

When rats are placed on periodic food schedules and have access to a drinking tube and a running wheel, multimodal activity distributions are observed within the interfood interval (Reid \& Bacha, 1984). For example, Roper (1978) and Staddon and Ayres (1975) observed that polydipsic drinking occurred early in the interfood inter$\mathrm{val}$ and wheel running occurred later, closer to the middle of the interval. Staddon (1977b) used this observation as a basis for the distinction between interim, or schedule-induced, activities occurring when reinforcement was least probable (just after food delivery) and facultative activities, which are not induced by the schedule of reinforcement and occur after the interim activity, near the middle of the interval.

From each of the distributions, it is apparent that none of the intervals were divided into interim activities and facultative activities: all activity distributions were unimodal, excluding contact with the water cup, the terminal activity.

Therefore, by all of the three criteria mentioned above for the classification as schedule-induced activity, no activities were schedule-induced, interim activities. Contact with the water cup was the only observed terminal, reward-related activity; all others were noninduced, facultative activities.

In Figure 2, the temporal distributions of the terminal activity and the other activities varied inversely. The inverse relation can be shown by carrying out a linear regression on the water cup area and each of the other activities. Since no activity was particularly prominent and there may be interactions between the facultative activities, the actual values of the slopes are of no importance; however, all slopes were negative (see below), demonstrating the inverse relation between the rate of each facultative activity and the rate of the terminal activity.

Of greater concern is the degree of control shown by the terminal activity over the distributions of each of the facultative activities. This control can be demonstrated by showing the influence of the terminal behavior on each facultative activity after the interactions between facultative activities have been eliminated. Multiple regression can demonstrate this influence, but regression on all activities would yield a correlation of 1.0 and be trivial, since the activities were exhaustive (however, the interactions would be informative even with a perfect correlation, since they could be either positive, representing facilitation, or negative, representing suppression). Since only four activities occurred at interesting levels, regression on only these four eliminates the problem. Table 2 gives the results of the multiple regression on only the four most prominent activities and solves the resulting simultaneous equations to give the direct interaction between the terminal behavior and each individual activity. The inverse relation between terminal and facultative activities is again 
Table 2

Multiple Regression on the Terminal Activity and Three of the Facultative Activities: Running, Grooming, and Sniffing

\begin{tabular}{lll}
\hline Ft Value & Regression Equation & $\mathbf{R}^{2}$ \\
\hline FT 15 sec & $\mathbf{W}=-5.0 \mathrm{R}+0.5$ & 0.79 \\
& $\mathrm{~W}=-4.1 \mathrm{G}+0.6$ & \\
& $\mathrm{~W}=-3.3 \mathrm{~S}+1.3$ & \\
FT $30 \mathrm{sec}$ & $\mathrm{W}=-1.0 \mathrm{R}+0.6$ & 0.94 \\
& $\mathrm{~W}=-1.3 \mathrm{G}+1.3$ & \\
& $\mathrm{~W}=-2.0 \mathrm{~S}+0.8$ & \\
FT $60 \mathrm{sec}$ & $\mathrm{W}=-5.1 \mathrm{R}+0.8$ & 0.80 \\
& $\mathrm{~W}=-1.8 \mathrm{G}+0.6$ & \\
& $\mathrm{~W}=-1.1 \mathrm{~S}+0.9$ & \\
FT 90 sec & $\mathrm{W}=-2.9 \mathrm{R}+1.2$ & 0.88 \\
& $\mathrm{~W}=4.0 \mathrm{G}-2.0$ & \\
& $\mathrm{~W}=-5.5 \mathrm{~S}+1.5$ & \\
FT $180 \mathrm{sec}$ & $\mathrm{W}=-13.8 \mathrm{R}+0.4$ & 0.64 \\
& $\mathrm{~W}=-0.4 \mathrm{G}+0.5$ & \\
\hline
\end{tabular}

Note $-W=$ water area $R=$ running wheel, $G=$ grooming; $S=$ sniffing.

demonstrated by the negative slopes, shown in 13 of the 15 cases. It is not clear why it was not shown in the two remaining cases, but the two cases represented different activities, that is, a single activity did not tend to have a positive relationship with the terminal activity as the interval duration was varied.

Recently, Reid and Dale (1983) did a similar analysis on the temporal distributions of schedule-induced drinking. They demonstrated that the interfood distributions of the terminal, food-related behavior determined the form of the schedule-induced drinking distributions. They argue (see, also, Reid \& Staddon, 1982) that manipulations of reward magnitude directly affect (and determine) the amount and distributions of terminal, reward-related behavior, which in turn determines the amount and distributions of interim behavior. In the present study, the inverse relation observed between the terminal, water-related behavior and each of the facultative behaviors demonstrates the same relationship: Frequency of water delivery directly determined the amount and distributions of terminal behavior, which in turn determined the amount and distributions of each of the facultative activities. We still cannot say which facultative activity will be most prominent, or why no activity becomes induced by these periodic water schedules. However, it is apparent that the distributions of facultative activities occurring when no activity is schedule-induced have the same form and are determined by the same factors as interim activities when facultative activities are not present in the interval, that is, when the activity distributions are unimodal.

It would be particularly interesting to determine if these relationships occur in intervals in which both interim and facultative activities are observed. Staddon's (1977a, 1977b) model predicts that the periodic reward would directly determine both the terminal and interim distributions, which would then determine the distributions of facultative behavior. As far as we know, this remains to be demonstrated. Would the determinants of interim and facultative distributions be the same in intervals in which subjects had access to both activity types but distributed each in separate intervals, as is occasionally the case (Penney \& Schull, 1977; Staddon \& Ayres, 1975)?

\section{REFERENCES}

Alurson, J., Miller, M., Wozny, M. (1979). Conservation in behavior. Joumal of Experimental Psychology: General, 108, 4-34.

COHEN, I. L. (1975). The reinforcing value of schedule-induced drinking. Journal of the Experimental Analysis of Behavior, 23, 37-44.

FALK, J. L. (1971). A theoretical review: The nature and determinants of adjunctive behavior. Physiology \& Behavior, 6, 577-588.

Heyman, G. M., \& BouZAS, A. (1980). Context dependent changes in the reinforcing strength of schedule-induced drinking. Journal of the Experimental Analysis of Behavior, 33, 327-336.

KING, G. D. (1974). Wheel-running in the rat induced by a fixed-time presentation of water. Animal Learning \& Behavior, 2, 325-328.

PENNEY, J., \& SCHULl, J. (1977). Functional differentiation of adjunctive drinking and wheel running. Animal Leaming \& Behavior, 5, 272-280.

RaCHLIN, H., \& BurKhard, B. (1978). The temporal triangle: Response substitution in instrumental conditioning. Psychological Review, 85, $22-47$.

Reid, A. K., \& BACHA, G. (1984). Cómo funciona: La investigación en el Laboratorio de Análisis Experimental de la Conducta. Información Cientifica Y Tecnologica, 6(88), 45-48.

REID, A. K., \& DALE, R. H. I. (1983). Dynamic effects of food magnitude on interim-terminal interaction. Joumal of the Experimental Analysis of Behavior, 39, 135-148.

REID, A. K., \& STADDON, J. E. R. (1982). Schedule-induced drinking: Elicitation, anticipation, or behavioral interaction? Journal of the Experimental Analysis of Behavior, 38, 1-18.

Riley, A. L., Wetherington, C. L., Delamater, A. R., Peele, D. B., \& DaCANAY, R. J. (1985). The effects of variations in the interpellet interval on wheel running in the rat. Animal Learning \& Behavior, 13, 201-206.

ROPER, T. J. (1978). Diversity and substitutability of adjunctive activities under fixed-interval schedules of food reinforcement. Journal of the Experimental Analysis of Behavior, 30, 83-96.

ROPER, T. J. (1980). Changes in rate of schedule-induced behavior in rats as a function of fixed-interval schedule. Quarterly Joumal of Experimental Psychology, 32, 159-170.

ROPER, T. J. (1981). What is meant by the term "schedule-induced,' and how general is schedule induction? Animal Learning \& Behavior, 9, 433-440.

STADDON, J. E. R. (1977a). Behavioral competition in conditioning situations: Notes toward a theory of generalization and inhibition. In H. Davis \& H. M. B. Hurwitz, Operant-Pavlovian interactions (pp. 103-131). Hillsdale, NJ: Erlbaum.

Staddon, J. E. R. (1977b). Schedule-induced behavior. In W. K. Ho nig \& J. E. R. Staddon (Eds.), Handbook of operant behavior (pp. 125 152). Englewood Cliffs, NJ: Prentice-Hall.

Staddon, J. E. R. (1979). Operant behavior as adaptation to constraint. Journal of Experimental Psychology: General, 108, 48-67.

STADDON, J. E. R. (1983). Adaptive behavior and learning. New York Cambridge University Press.

Staddon, J. E. R. \& AYres, S. (1975). Sequential and temporal properties of behavior induced by a schedule of periodic food delivery. Behaviour, 54, 26-49.

WETHERINGTON, C. L. (1979). Schedule-induced drinking: Rate of food delivery and Herrnstein's equation. Joumal of the Experimental Anal. ysis of Behavior, 32, 323-334.

Wetherington, C. L., Brownstein, A. J. (1979). Schedule control of eating by fixed-time schedules of water presentation. Animal Leaming \& Behavior, 7, 38-40.

(Manuscript received October 31, 1984; revision accepted for publication July 22, 1985.) 